\title{
Qualitative and quantitative HPLC-ELSD-ESI-MS analysis of steroidal saponins in fenugreek seed
}

BARBARA KRÓL-KOGUS

DANIEL GEÓD

MIROSEAWA KRAUZE-BARANOWSKA*

Department of Pharmacognosy with Medicinal Plants Garden Medical University of Gdańsk 80-416 Gdańsk, Poland
Accepted March 19, 2019

Published online April 24, 2019

\begin{abstract}
Fenugreek seeds are known as a source of various compounds, the most common of which are steroidal saponins. However, despite the growing interest in this plant material as a healing agent, spice and dietary supplement ingredient, the composition of Polish fenugreek seeds remains unknown. Therefore, the steroidal saponin complex in the seeds of T. foenum-graecum cultivated in Poland was qualitatively and quantitatively analyzed by the HPLC-ELSDESI-MS method. Two C-18 columns connected in series were used for the first time in analysis of fenugreek saponins and ELS detector parameters were optimized. A total of 26 furostanol saponins were revealed, of which 24 were tentatively identified. The HPLC-ELSD method developed for quantitative analysis was preliminarily validated and the determined amount of steroidal saponins in Polish fenugreek seeds was $0.14 \%$.
\end{abstract}

Keywords: fenugreek seeds, saponins, HPLC-ELSD-ESI-MS, qualitative and quantitative analysis

Fenugreek (Trigonella foenum-graecum, Fabaceae) is an annual, herbaceous plant, originating from the Mediterranean region and cultivated all over Europe. Fenugreek seeds are known to contain several groups of secondary metabolites, of which, besides flavones (1, $2)$, isoflavones (1) and polysaccharides (3), the most abundant are steroidal saponins (2, 4-12). The complex of steroidal saponins in fenugreek seeds is composed of different spirostanol and furostanol saponins with straight or branched sugar chains $(2,4-12)$. The main aglycones are diosgenin and its 25-epimer yamogenin (6). Research on saponins occurring in Trigonella foenum-graecum seeds was the subject of many independent studies $(2,4-12)$ and, as a result, different common names have been given to compounds of the same chemical structure, e.g., protodioscin/compound C, protoneodioscin/trigonelloside C $(2,4,6-9,11,13-16)$.

Most fenugreek saponins were isolated and structurally recognized by spectroscopic methods (7-9, 11, 13-16); however, some of them were identified with the aid of hyphenated

*Correspondence; e-mail address: krauze@gumed.edu.pl 
techniques like HPLC-MS/MS (2, 4, 6). HPLC equipped with a light diffusion detector was applied to fenugreek saponin analysis only by Petit et al. (17), though it is the method of choice in steroidal saponin separation in plant matrices (18-20). Protodioscin was described as a major saponin of fenugreek seeds $(21,22)$. Steroidal saponins are responsible or co-responsible for several pharmacological effects of fenugreek seeds, including antidiabetic, hypolipidemic, anti-inflammatory and anticancer effects $(14,23,24)$. Thus far, most studies have analyzed saponins in the fenugreek seeds of Asian origin. As T. foenum-graecum seeds are now becoming increasingly popular as a healing agent and a component of various dietary supplements, their chemical composition must be known because it determines the efficacy and safety of their use. The aim of this work was to analyze qualitatively and quantitatively steroidal saponins in the seeds of $T$. foenum-graecum from Poland using the HPLC-ELSD-ESI-MS method.

\section{EXPERIMENTAL}

\section{Materials and reagents}

LC-MS grade acetonitrile and analytical grade formic acid were purchased from Merck (Germany). Water from a Millipore system (Merck) was used in all experiments. The protodioscin standard was purchased from Sigma-Aldrich (USA).

\section{Plant material and sample preparation}

Fenugreek (Trigonella foenum-graecum) seeds obtained from the herbal company FZL (Kruszynek, Poland) were cultivated in central Poland, collected when mature and dried. Five grams (5.0 g) of dried fenugreek seeds were ground in an electric grinder and extracted with $70 \%$ methanol $(2 \times 3 \mathrm{~h}, 2 \times 100 \mathrm{~mL})$ at $60{ }^{\circ} \mathrm{C}$ using a magnetic stirrer. The obtained extract was lyophilized, dissolved in methanol (1:1) and filtered through a 0.22- $\mu$ m nylon syringe filter (ChemLand, Poland) before HPLC analysis.

\section{HPLC systems}

The HPLC system (Shimadzu, Japan) consisted of two LC-20AD pumps, degasser DGU-20A5, semi-micro mixer (100 mL for HPLC-ESI-MS and 0.5-2.6 mL for HPLC-ELSD), controller CBM-20A, thermostat CTO-20AC, autosampler SIL 20AC $\mathrm{XR}_{\mathrm{X}}$, nitrogen generator (Peak Scientific, UK), LCMS-2020 mass spectrometer with ESI ionization and evaporative light scattering detector ELSD 3300 (Alltech Associates, USA). Data was acquired and processed by LabSolution software (version 1.2).

The mobile phase consisted of A - water: formic acid (99.9:0.1, V/V) and B - acetonitrile: formic acid (99.9:0.1, V/V). Separation was performed first on a Discovery C-18 column (150 $\mathrm{mm} \times 2.1 \mathrm{~mm}, 3 \mu \mathrm{m}$ ) according to gradient program I: $0 \mathrm{~min}-20 \% \mathrm{~B}, 27 \mathrm{~min}-33.5 \% \mathrm{~B}, 45$ $\min -100 \% \mathrm{~B}$. Then, saponins were separated on two Discovery C-18 columns $(150 \mathrm{~mm} \times$ $2.1 \mathrm{~mm}, 3 \mu \mathrm{m}$, each) connected in series according to gradient program II: $0 \mathrm{~min}-20 \% \mathrm{~B}$, $54 \mathrm{~min}-33.5 \% \mathrm{~B}, 90 \mathrm{~min}-100 \% \mathrm{~B}$. Column temperature was $20^{\circ} \mathrm{C}$ and the flow rate was $0.2 \mathrm{~mL} \mathrm{~min}^{-1}$. Injection volume was $1 \mu \mathrm{L}$. 


\section{HPLC-ELSD conditions}

ELS detector parameters were experimentally assorted and optimized in the following range: evaporator temperature $40-50{ }^{\circ} \mathrm{C}$, signal strength $4-8$, nebulizing gas $\left(\mathrm{N}_{2}\right)$ flow 1.3-2.0 $\mathrm{L} \mathrm{min}^{-1}$.

\section{ESI-MS conditions}

Mass spectra were acquired using a Shimadzu LCMS 2020 in positive (PI) and negative (NI) ion modes. A full-scan (range $\mathrm{m} / \mathrm{z}$ 800-1600) and SIM (selected ion monitoring) technique for monitoring specific signals was used. The MS detector parameters were: ESI voltage $4.5 \mathrm{kV}$, nebulizing gas $\left(\mathrm{N}_{2}\right)$ flow $1.5 \mathrm{~L} \mathrm{~min}^{-1}$, desolvation line and block temperatures were: 250 and $200{ }^{\circ} \mathrm{C}$, resp., and drying gas flow $\left(\mathrm{N}_{2}\right)$ was $8.5 \mathrm{~L} \mathrm{~min}^{-1}$. Detector voltage was $2 \mathrm{kV}$ and drying gas flow $\left(\mathrm{N}_{2}\right)$ was $10 \mathrm{~L} \mathrm{~min}^{-1}$.

\section{Method validation}

The method developed for the purpose of quantitative analysis was preliminarily validated in terms of specificity, calibration/linearity, limit of detection $(L O D)$, limit of quantitation $(L O Q)$, and intra-day and inter-day precision. The data are given in Table I.

Identity of protodioscin in the sample was proven by comparison of the retention time of peak $18\left(t_{\mathrm{R}} 36.98 \mathrm{~min}\right)$ and that of the reference substance $\left(t_{\mathrm{R}} 36.98 \mathrm{~min}\right)$, as well as by comparison of the obtained ESI-MS spectrum data for peak $\mathbf{1 8}$ and the reference substance. Total amount of saponins was expressed as protodioscin and a calibration curve was constructed for protodioscin. Stock solution of protodioscin in methanol $\left(1 \mathrm{mg} \mathrm{mL}^{-1}\right)$ was diluted with methanol and the regression curve was determined on the basis of the analysis of the plot of the peak area for protodioscin $(75,120,150,240,300,600,750,200,1500,2400$ $\left.\mu \mathrm{g} \mathrm{mL}^{-1}\right)$. LOD and LOQ were determined as the concentration of the standard compound equaling $3 \times$ and $10 \times$ of the signal-to-noise ratio, resp.

Intra-day precision was assessed by analyzing continuous injections of the same sample $\left(0.24 \mathrm{mg} \mathrm{mL}^{-1}\right.$ of protodioscin) within one day $(n=5)$, while the inter-day precision was evaluated by analyzing injections of the same sample $\left(0.24 \mathrm{mg} \mathrm{mL}^{-1}\right.$ of protodioscin) for five consecutive days ( $n=5$ per day). Intra- and inter-day precision were expressed as RSD.

Table I. Validation parameters of the established HPLC-ELSD method for determination of steroidal saponins in fenugreek seeds

\begin{tabular}{cc}
\hline Regression equation & $y=x^{0.586726 \text { on equat }}$ \\
\hline Coefficient of determination & $R^{2}=0.999$ \\
LOD $\left(\mu \mathrm{g} \mathrm{mL}^{-1}\right)$ & 48.99 \\
LOQ $\left(\mu \mathrm{g} \mathrm{mL}^{-1}\right)$ & 146.97 \\
Inter-day precision (RSD, \%) & 1.92 \\
Intra-day precision (RSD, \%) & 1.80 \\
\hline
\end{tabular}




\section{RESULTS AND DISCUSSION}

\section{HPLC-ELSD-ESI-MS separation}

Chromatographic analysis of steroidal saponins in fenugreek seeds with standard analytical tools is laborious, not only due to their complicated chemical structure and the presence of usually more than two isomers (including 25-epimers) of the same molecular mass, but also due to the lack of commercially available reference substances (with the exception of protodioscin). The detector routinely applied in the HPLC analysis of saponins is ELSD (18-20) since it is known to be universal and sensitive, while the use of a UV detector is inadvisable due to the lack of chromophores in saponin molecules. However, some authors observed separation of saponins by employing UV detection at low wavelengths in a range of $200-210 \mathrm{~nm}(25,26)$.

Use of HPLC hyphenated with detectors MS and ELSD has been so far reported for identification of saponins in the fenugreek seeds of Asian origin (UPLC-ESI-QTOF-MS ${ }^{n}$ ) $(2,4,6)$ and those obtained from an experimental cultivar in France (HPLC-LDD) (17). Using LC coupled with a light diffusion detector on a Kromasil RP-18 column $(250 \times 4.6$ mm,

a)

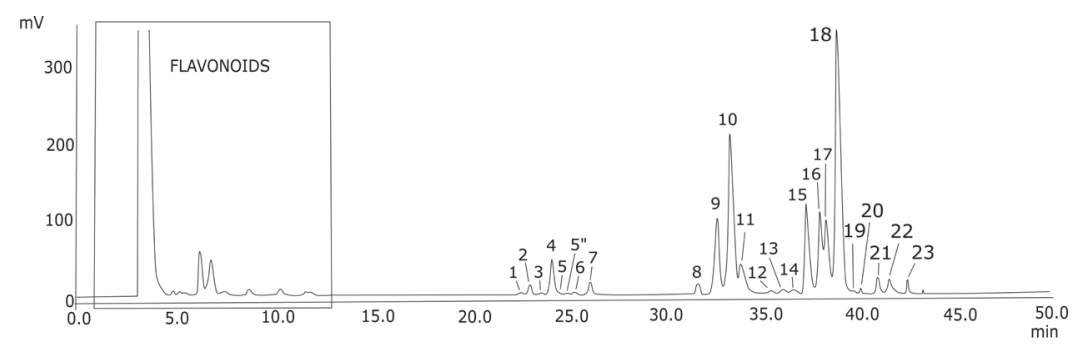

$\mathrm{mV}$

b)

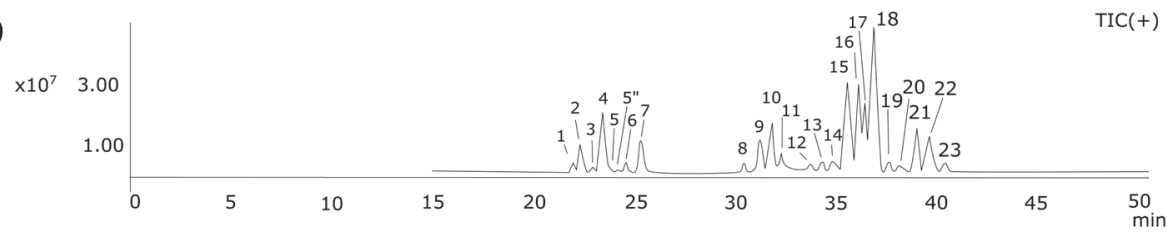

$\mathrm{mV}$

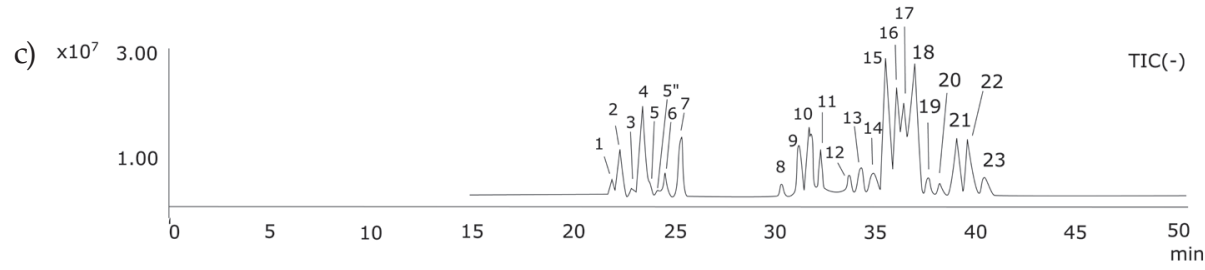

Fig. 1. HPLC-ELSD-ESI-MS chromatograms of steroidal saponins from fenugreek seeds of Polish origin: a) HPLC-ELSD and b) and c) HPLC-ESI-MS [Discovery C-18 $(2 \times 150 \mathrm{~mm} \times 2.1 \mathrm{~mm}, 3 \mu \mathrm{m})$ columns, gradient elution, program II]. 
$5 \mu \mathrm{m})$, Petit et al. (17) obtained separation of fenugreek saponins in the form of 4 peaks in $30 \mathrm{~min}$.

On the basis of literature data $(6,27)$, the mobile phase used in our experiments was water/acetonitrile to eliminate the formation of methoxy C-22 derivatives of furostanol saponins with a free hydroxyl group at this position. Moreover, Kang et al. (6) analyzed the concentration of formic acid in the mobile phase and observed the best shape of saponin peaks at a concentration of $0.1 \%$. Therefore, the final mobile phase in our experiments was water/acetonitrile with addition of $0.1 \%$ formic acid. Gradient program started from the initial $20 \%$ concentration of acetonitrile/formic acid (99.9:0.1, V/V) in water and the profile of gradient elution as well as the parameters of ELS detector (evaporator temperature, signal strength and nebulizing gas flow rate) were established experimentally. The best ELS detection was achieved at $40{ }^{\circ} \mathrm{C}$ of the evaporator, signal strength 4 and nebulizing gas $\left(\mathrm{N}_{2}\right)$ flow rate of $1.8 \mathrm{~L} \mathrm{~min}^{-1}$.

HPLC separation of steroidal saponins is usually performed in RP systems, on C-18, $\mathrm{C}-8, \mathrm{NH}_{2}$ or diol columns $(25,27,28)$. In our experiments, the HPLC-ELSD separation was initially performed on a single Discovery C-18 column under gradient elution, according to program I (data not shown). Use of two Discovery C-18 columns $(2 \times 150 \times 2.1 \mathrm{~mm}, 3 \mu \mathrm{m})$ connected in series increased the migration distance of analyzed compounds and, after optimization of gradient elution program (program II), led to their better separation (Fig. 1). HPLC separation with the use of two columns connected in series was applied for the analysis of fenugreek saponins for the first time. As a result, separation of saponins as 24 peaks was achieved. ESI-MS analyses were performed in both positive (PI) and negative (NI) ion modes and the SIM technique was used.

\section{Identification of steroidal saponins}

According to literature data (6), steroid saponins under ESI ionization in positive ion (PI) mode form adducts with $\mathrm{Na}(\mathrm{M}+\mathrm{Na})^{+}$and $\left(\mathrm{M}+\mathrm{H}-\mathrm{H}_{2} \mathrm{O}\right)^{+}$ions, while in negative ion (NI) mode deprotonated molecular ions $(\mathrm{M}-\mathrm{H})^{-}$and adducts with formic acid $(\mathrm{M}-\mathrm{H}+\mathrm{HCOO})^{-}$ were detected. Recognition of the steroid saponin complex in fenugreek seeds of Polish origin was possible by comparing the obtained spectral data $(\mathrm{m} / \mathrm{z}$ values of molecular ions and various types of adducts) and chromatographic data (values of $t_{R^{\prime}}$ elution order) with literature data (4-12). As a result, the presence of 26 steroidal saponins was disclosed, of which $24(1-18,21-23)$ were assigned structures of compounds previously identified in the fenugreek seeds of Asian and African origin (2, 4, 6-10). Compound/peak 18 was confirmed to be protodioscin upon $t_{\mathrm{R}}$ compared to that of the reference substance (36.98 min in both cases), as well as by comparison of the obtained ESI-MS data for peak $\mathbf{1 8}$ and the reference substance. Although the applied analytical tool enabled recognition of 26 compounds in fenugreek seeds, it was impossible to identify unseparated 25R and 25S epimers. The obtained chromatographic and spectral data and tentative identification of steroidal saponins in Polish plant material are presented in the Table II.

In the ESI mass spectrum of compound 19, obtained in PI mode, two types of signals were present: at $m / z 1073$, being an adduct with sodium $(\mathrm{M}+\mathrm{Na})^{+}$, and at $m / z 1033$ corresponding to the $\left(\mathrm{M}+\mathrm{H}-\mathrm{H}_{2} \mathrm{O}\right)^{+}$ion. In NI mode, compound 19 produced a deprotonated molecular ion at $m / z 1049(\mathrm{M}-\mathrm{H})^{-}$and an adduct with formic acid at $m / z 1095(\mathrm{M}-\mathrm{H}+\mathrm{HCOO})^{-}$. Compound 20 in PI mode gave ions at $m / z$ 923, corresponding to the adduct with sodium 


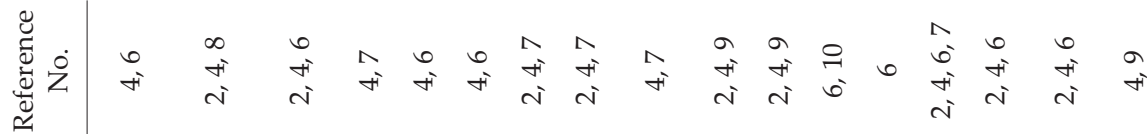

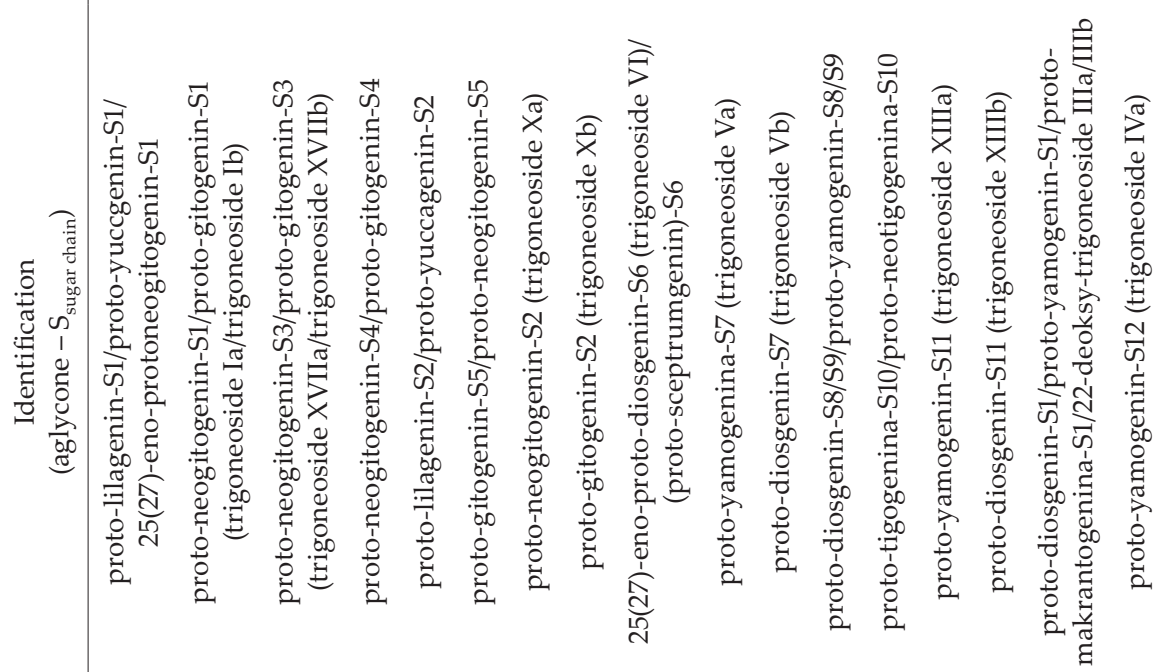

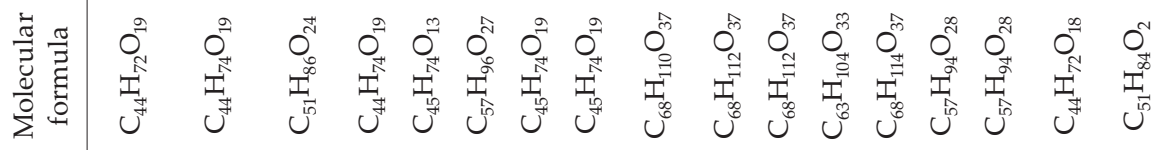

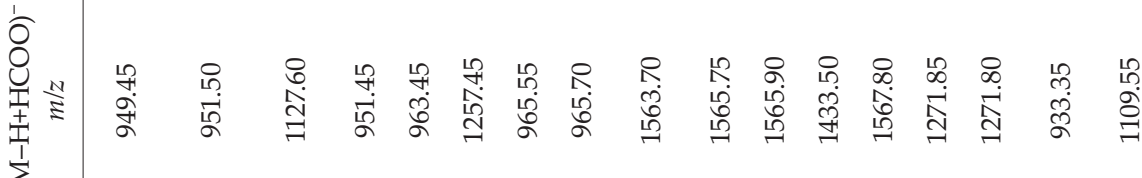
$\sum$

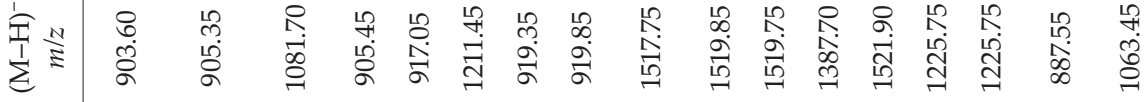

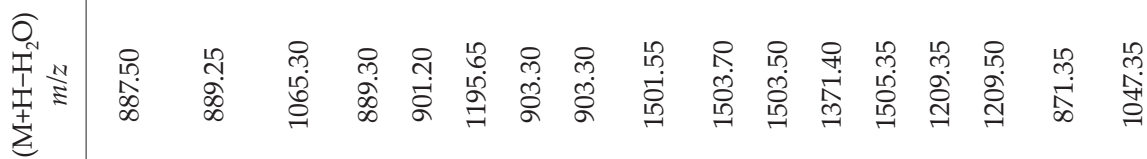

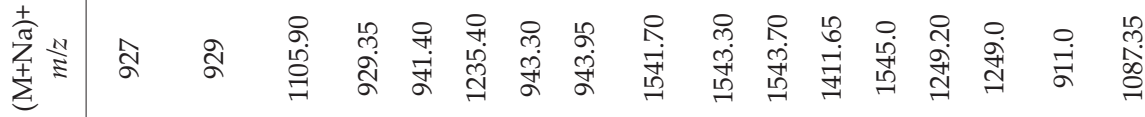

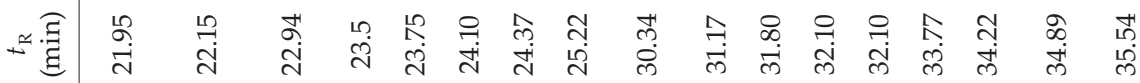

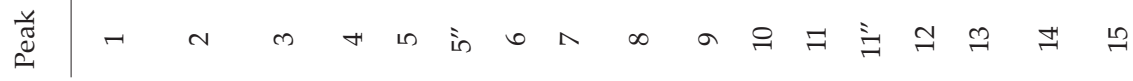




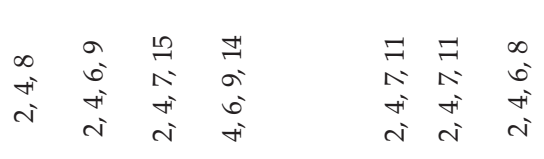

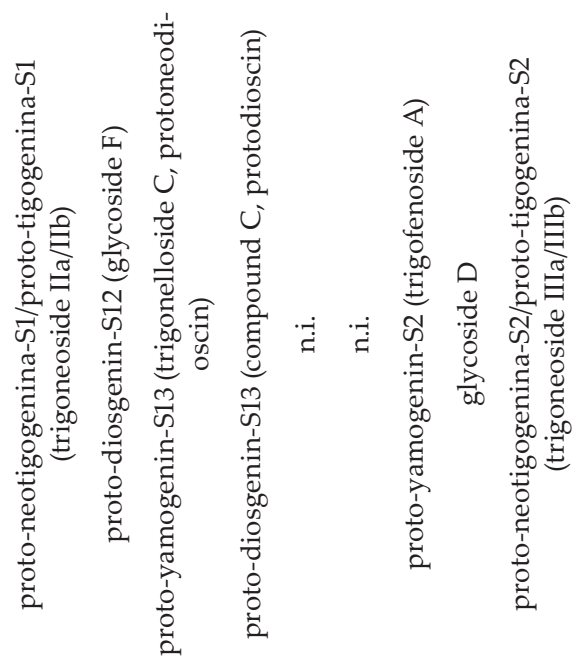

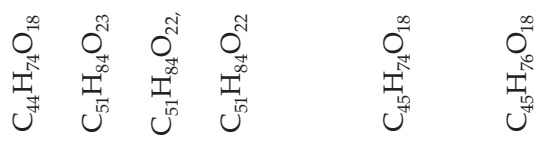

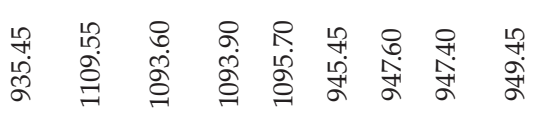

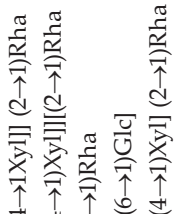

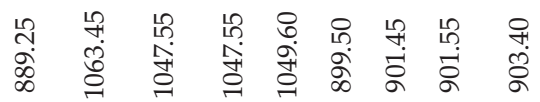

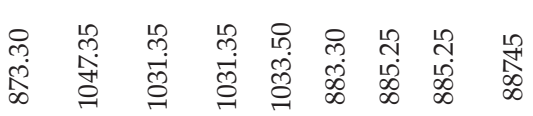

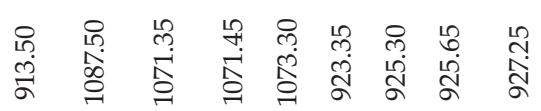

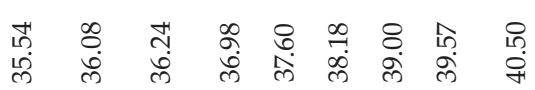

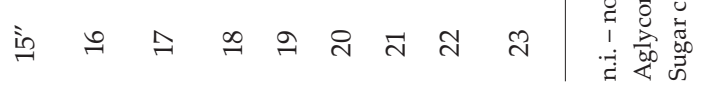


$(\mathrm{M}+\mathrm{Na})^{+}$and at $m / z 883$ being the $\left(\mathrm{M}+\mathrm{H}-\mathrm{H}_{2} \mathrm{O}\right)^{+}$ion. In NI, two signals were abundant: at $\mathrm{m} / \mathrm{z} 899$ [deprotonated molecular ion $(\mathrm{M}-\mathrm{H})^{-}$] and at $\mathrm{m} / \mathrm{z} 945$ [adduct with formic acid (M$\left.\mathrm{H}+\mathrm{HCOO})^{-}\right]$. The data obtained for compounds $\mathbf{1 9}$ and $\mathbf{2 0}$ did not correspond to any of the steroidal saponins previously identified in fenugreek seeds $(1-18,21-23)$. However, the compound demonstrating signals at the same $\mathrm{m} / \mathrm{z}$ values as those obtained for compound 19 was revealed in HPLC-ESI-MS analysis of Ruscus tubers and leaves and was identified as (25R)-25,27-dihydroruscoside (29).

Yoshikawa et al. (30) isolated from male flowers of Borassus flabellifer two isomeric steroidal saponins with the molecular formula $\mathrm{C}_{45} \mathrm{H}_{72} \mathrm{O}_{18}$, which corresponds to the data obtained for compound 20. Using high resolution mass spectrometry with fast atom bombardment, the authors showed that both isolated compounds were derivatives of $23 \alpha, 27-$ dihydroxy-diosgenin and $23 \alpha, 27-$ dihydroxy-yamogenin with the chain of $\beta$-D-glucopyranosyl-( $4 \rightarrow 1) \alpha$-L-rhamnopyranosyl)-(2 $\rightarrow 1) \alpha$-L-rhamnopyranose at C-3 of aglycone (30). Taking into account the presence of proto-diosgenin and proto-yamogenin glycosides in fenugreek seeds, it seems possible that also the glycosides of their $23 \alpha$,27-dihydroxyderivatives may appear in this plant material. However, full identification of compounds 19 and 20 requires isolation and structure elucidation.

In the HPLC-ELSD-ESI-MS chromatographic profile of steroidal saponins from Polish fenugreek seeds, the most abundant were protodioscin (compound 18) and trigoneoside $\mathrm{Vb}$ (compound 10). At lower concentrations, trigoneoside IVa (compound 15) and its 25Repimer - glucoside F (compound 16), trigoneoside Va (compound 9) and protoneodioscin (compound 17) were present. These compounds are mostly derivatives of diosgenin (compounds $\mathbf{1 0}, \mathbf{1 6}, \mathbf{1 8}$ ) and its 25S-epimer - yamogenin (compounds $9, \mathbf{1 5}, \mathbf{1 7}$ ), being the main source of diosgenin released during acid hydrolysis. It has been reported that $25 S$ and $25 R$ sapogenins mutually epimerize $(5,27,28)$; therefore, under acidic conditions, yamogenin may be converted to diosgenin.

Comparing the obtained HPLC profile of fenugreek saponins with some literature data, significant differences were found between plant materials of different geographical origin. For example, in the UPLC-ESI-Q/TOF-MS (low CE full scan) analysis of Chinese fenugreek seeds, the most intensive was the peak of a mixture of trigonelloside $\mathrm{C}$ (protoneodioscin) and an unknown furostanol saponin of molecular formula $\mathrm{C}_{51} \mathrm{H}_{86} \mathrm{O}_{23}$ (2). A slightly lower intensity characterized the peaks of mixtures of trigoneoside Ia with trigoneoside XVIIb and trigoneoside Ib with trigoneoside XVIIa (2). Considering the type of aglycone, it should be noted that in the fenugreek seeds of Chinese origin, besides protoneodioscin being the derivative of proto-yamogenin, the most abundant saponins are derivatives of proto-neogitogenin (trigoneosides Ia and XVIIa) and proto-gitogenin (trigoneosides Ib and XVIIb) (4), while in Polish plant material these compounds are present only in trace amounts (Fig. 1, Table II). On the other hand, in the Indian fenugreek seeds, protodioscin was recognized by HPTLC as the most abundant compound (22).

\section{Quantitative analysis}

Quantitative analysis of steroidal saponins was performed under the established HPLC-ELSD method conditions as described above. The method was preliminarily validated and the results are presented in Table I. In the studied range of concentrations, 
the regression curve showed a non-linear relationship, which is consistent with literature data $(31,32)$.

The total amount of steroidal saponins identified in Polish fenugreek seeds was 0.14 $\%$ on $\mathrm{dm}$ basis while the total steroidal saponin content in T. foenum-graecum seeds of different genotypes from the Indian National Bank of Genomes, determined by spectrophotometric methods, ranged from 0.92 to $1.68 \mathrm{~g}$ per $100 \mathrm{~g}$ of dry matter (33). Also, Madhava Naidu et al. (34), analyzing fenugreek seeds of Indian origin, showed a steroidal saponin content of $5.12 \mathrm{~g}$ per $100 \mathrm{~g} \mathrm{dm}$, while the amount of these compounds in Chinese fenugreek seeds determined by Wang et al. (2) was $6 \%$ of dry matter. In contrast to these data, the Polish plant material has a relatively low content of steroidal saponins.

\section{CONCLUSIONS}

A HPLC-ELSD-ESI-MS method, comprising separation on two columns connected in series, for qualitative and quantitative analysis of saponins, was established. Polish fenugreek seeds were recognized as containing a relatively small amount of steroidal saponins in comparison with Asian plant material. In addition, it was found that other saponins predominated in the seeds of Polish origin compared to Chinese samples. Also, although in both Polish and Indian fenugreek seeds protodioscin was most abundant, the other dominant compounds (saponins) were different. This paper is the first report on the composition of steroidal saponins of fenugreek seeds of Polish origin. In addition, the established HPLC-ELSD-ESI-MS method may be used for analyses of other plant matrices containing steroidal saponins.

Acknowledgements. - This work was supported by the Polish Ministry of Science and Higher Education (project no. MN 0-0024/08).

\section{REFERENCES}

1. B. Król-Kogus, D. Głód, M. Krauze-Baranowska and I. Matławska, Application of one-and twodimensional high-performance liquid chromatography methodologies for the analysis of C-glycosylflavones from fenugreek seeds, J. Chrom. A 1367 (2014) 48-56; https://doi.org/10.1016/j.chroma.2014.09.039

2. J. Wang, W. Jiang, Z. Liu, T. Fu and Y. Wang, Analysis and identification of chemical constituents of fenugreek by UPLC-IT-MS ${ }^{n}$ and UPLC-Q-TOF-MS, Chem. Res. Chin. Univ. 33 (2017) 721-730; https://doi.org/10.1007/s40242-017-7136-4

3. V. Mathur and N. K. Mathur, Fenugreek and other lesser known legume galactomannan-polysaccharides: Scope for developments, J. Sci. Ind. Res. 64 (2005) 475-481.

4. X. Pang, L. Kang, H. Yu, Y. Zhao, C. Xiong, J. Zhang, J. Shan and B. P. Ma, Rapid isolation of new furostanol saponins from fenugreek seeds based on ultra-performance liquid chromatography coupled with a hybrid quadrupole time-of-flight tandem mass spectrometry, J. Sep. Sci. 35 (2012) 1538-1550; https://doi.org/10.1002/jssc.201200020

5. X. Pang, Y. Cong, H. S. Yu, L. P. Kang, B. Feng, B. X. Han, Y. Zhao, C. Xiong, D. Tan, W. Song, B. Liu, Y. Cong and B. P. Ma, Spirostanol saponins derivated from the seeds of Trigonella foenumgraecum by $\alpha$-glucosidase hydrolysis and their inhibitory effects on rat platelet aggregation, Planta Med. 78 (2012) 276-285; https://doi.org/10.1055/s-0031-1280373 
B. Król-Kogus et al.: Qualitative and quantitative HPLC-ELSD-ESI-MS analysis of steroidal saponins in fenugreek seed, Acta Pharm. 70 (2020) 89-99.

6. L. P. Kang, Y. Zhao, X. Pang, H. S. Yu, C. Q. Xiong, J. Zhang, Y. Gao, K. Yu, C. Liu and B. Ma, Characterization and identification of steroidal saponins from the seeds of Trigonella foenum-graecum by ultra high-performance liquid chromatography and hybrid time-of-flight mass spectrometry, J. Pharm. Biomed. Anal. 74 (2013) 257-267; https://doi.org/10.1016/j.jpba.2012.11.005

7. T. Murakami, A. Kishi, H. Matsuda and M. Yoshikawa, Medicinal foodstuffs. XVII. Fenugreek seed. (3): Structures of new furostanol-type steroid saponins, trigoneosides Xa, Xb, XIb, XIIa, XIIb, and XIIIa, from the seeds of egyptian Trigonella foenum-graecum L., Chem. Pharm. Bull. 48 (2000) 994-1000; https://doi.org/10.1248/cpb.48.994

8. M. Yoshikawa, T. Murakami, H. Komatsu, N. Murakami, J. Yamahara and H. Matsuda, Medicinal foodstuffs. IV. Fenugreek seed. (1): Structures of trigoneosides Ia, Ib, IIa, IIb, IIIa, and IIIb, new furostanol saponins from the seeds of Indian Trigonella foenum-graecum L, Chem. Pharm. Bull. 45 (1997) 81-87; https://doi.org/10.1248/cpb.45.81

9. M. Yoshikawa, T. Murakami, H. Komatsu, J. Yamahara and H. Matsuda, Medicinal foodstuffs. VIII.1 Fenugreek seed. (2): Structures of six new furostanol saponins, trigoneosides IVa, Va, Vb, VI, VIIb, and VIIIb, from the seeds of Indian Trigonella foenum-graecum L., Heterocycles 47 (1998) 397-405; https://doi.org/10.1002/chin.199816214

10. X. Pang, H. S. Yu, L. P. Kang, B. Feng, Y. Zhao, C. Q. Xiong, D. W. Tan D, W. Song W, B. Liu and B. P. Ma, Two new furostanol saponins from the seeds of Trigonella foenum-graecum, J. Asian Nat. Prod. Res. 13 (2011) 611-617; https://doi.org/10.1080/10286020.2011.579073

11. R. K. Gupta, D. C. Jain and R. S. Thakur, Furostanol glycosides from Trigonella foenum-graecum seeds, Phytochemistry 24 (1985) 2399-2401; https://doi.org/10.1016/S0031-9422(00)83050-2

12. V. K. Saxena and A. Shalem, Yamogenin 3-O- $\beta$-D-glucopyranosyl $(1 \rightarrow 4)-O-\alpha$-D-xylopyranoside from the seeds of Trigonella foenum-graecum, J. Chem. Sci. 116 (2004) 79-82; https://doi.org/10.1007/ BF02708199

13. T. Kawasaki, T. Komori and K. Miyahara, Furostanol bisglycosides corresponding to dioscin and gracillin, Chem. Pharm. Bull. 22 (1974) 2164-2175; https://doi.org/ 10.1248/cpb.22.2164

14. H. Hibasami, H. Moteki, K. Ishikawa, H. Katsuzaki, K. Imai, K. Yoshioka, Y. Ishii and T. Komiya, Protodioscin isolated from fenugreek (Trigonella foenum-graecum L.) induces cell death and morphological change indicative of apoptosis in leukemic cell line H-60, but not in gastric cancer cell line KATO III, Int. J. Mol. Med. 11 (2003) 23-26; https://doi.org/10.3892/ijmm.11.1.23

15. N. G. Bogacheva, V. P. Kiselev and L. M. Kogan, Isolation of 3,26-bisglycoside of yamogenin from Trigonella foenum-graecum, Chem. Nat. Comp. 12 (1976) 242-243.

16. R. K. Gupta, D. C. Jain and R. S. Thakur, Furostanol glycosides from Trigonella foenum-graecum seeds, Phytochemistry 23 (1984) 2605-2607; https://doi.org/10.1007/BF00566366

17. P. R. Petit, Y. D. Sauvaire, D. M. Hillaire-Buys, O. M. Leconte, Y. G. Baissac, G. R. Ponsin and G. R. Ribes, Steroid saponins from fenugreek seeds: Extraction, purification, and pharmacological investigation on feeding behavior and plasma cholesterol, Steroids 60 (1995) 674-680; https://doi. org/10.1016/0039-128X(95)00090-D

18. A. M. Leal-Díaz, L. Santos-Zea, H. C. Martínez-Escobedo, D. Guajardo-Flores, J. A. GutiérrezUribe and S. O. Serna-Saldivar, Effect of Agave americana and Agave salmiana ripeness on saponin content from aguamiel (Agave Sap), J. Agric. Food Chem. 63 (2015) 3924-3930; https://doi.org/ 10.1021/acs.jafc.5b00883

19. M. Tenon, N. Feuillère, M. Roller and S. Birtić, Rapid, cost-effective and accurate quantification of Yucca schidigera Roezl. steroidal saponins using HPLC-ELSD method, Food Chem. 221 (2017) 12451252; https://doi.org/10.1016/j.foodchem.2016.11.033

20. X. Zhang, J. Liang, J. Liu, Y. Zhao, J. Gao, W. Sun and Y. Ito, Quality control and identification of steroid saponins from Dioscorea zingiberensis C. H. Wright by fingerprint with HPLC-ELSD and 
B. Król-Kogus et al.: Qualitative and quantitative HPLC-ELSD-ESI-MS analysis of steroidal saponins in fenugreek seed, Acta Pharm. 70 (2020) 89-99.

HPLC-ESI-quadrupole/time-of-fight tandem mass spectrometry, J. Pharm. Biol. Anal. 91 (2014) 46-59; https://doi.org/10.1016/j.jpba.2013.11.023

21. K. Taketani, S. Hoshino, T. Uemura, T. Goto, N. Takahashi, N. Tsuge and T. Kawada, An efficient purification method for quantitative determinations of protodioscin, dioscin and diosgenin in plasma of fenugreek-fed mice, J. Nutr. Sci. Vitaminol. 61 (2015) 465-470; https://doi.org/10.3177/ jnsv.61.465

22. K. Variya and V. Parmar, A validated high-performance thin-layer chromatographic method for the quantitation of protodioscin in Trigonella foenum-graecum and its herbal formulations, J. Planar. Chromatogr. - Mod. TLC 28 (2015) 458-465; https://doi.org/ 10.1556/1006.2015.28.6.7

23. F. R. Lu, L. Shen, Y. Qin and L. Gao, Clinical observation of Trigonella foenum-graecum saponin combining sulphanylureas on 36 cases of type 2 diabetes mellitus, Chin. J. Integr. Med. 33 (2008) 184-187; https://doi.org/10.1007/s11655-007-9005-3

24. T. Kawabata, M.-Y. Cui, T. Hasegawa, F. Takano and T. Ohta, Anti-inflammatory and anti-melanogenic steroidal saponin glycosides from fenugreek (Trigonella foenum-graecum L.) seeds, Planta Med. 77 (2011) 705-710; https://doi.org/10.1055/s-0030-1250477

25. W. Oleszek and Z. Bialy, Chromatographic determination of plant saponins - An update (20022005), J. Chrom. A 1112 (2006) 78-91; https://doi.org/ 10.1016/j.chroma.2006.01.037

26. D. J. Yang, T. J. Lu and L. S. Hwang, Simultaneous determination of furostanol and spirostanol glycosides in Taiwanese yam (Dioscorea spp.) cultivars by high performance liquid chromatography, J. Food Drug Anal. 11 (2003) 271-276.

27. G. C. Kite, E. A. Porter and M. S. J. Simmonds, Chromatographic behaviour of steroidal saponins studied by high-performance liquid chromatography-mass spectrometry, J. Chrom. A 1148 (2007) 177-183; https://doi.org/ 10.1016/j.chroma.2007.03.012

28. J. S. Negi, P. Singh, G. J. N. Pant and M. S. M. Rawat, High-performance liquid chromatography analysis of plant saponins: An update 2005-2010, Pharmacogn. Rev. 5 (2011) 155-158; https://doi.org/ 10.4103/0973-7847.91109

29. E. De Combarieu, M. Falzoni, N. Fuzzati, F. Gattesco, A. Giori, M. Lovati and R. Pace, Identification of Ruscus steroidal saponins by HPLC-MS analysis, Fitoterapia 73 (2002) 583-596; https://doi.org/ 10.1016/S0367-326X(02)00220-4

30. M. Yoshikawa, F. Xu, T. Morikawa, Y. Pongpiriyadacha, S. Nakamura, Y. Asao, A. Kumahara and H. Matsuda, Medicinal flowers. XII. New spirostane-type steroid saponins with antidiabetogenic activity from Borassus flabellifer, Chem. Pharm. Bull. 55 (2007) 308-316; https://doi.org/10.1248/ cpb.55.308

31. Z. Witkiewicz and J. Kałużna-Czaplińska, Podstawy Chromatografii i Technik Elektromigracyjnych, Wydawnictwo WNT, Warszawa 2012.

32. N. Vervoort, D. Daemen and G. Török, Performance evaluation of evaporative light scattering detection and charged aerosol detection in reversed phase liquid chromatography, J. Chrom. A 1189 (2008) 92-100; https://doi.org/10.1016/j.chroma.2007.10.111

33. M. Arivalagan, K. K. Gangopadhyay and G. Kumar, Determination of steroidal saponins and fixed oil content in fenugreek (Trigonella foenum-graecum) genotypes, Indian J. Pharm. Sci. 75 (2013) 110-113; https://doi.org/10.4103/0250-474X.113542

34. M. M. Naidu, B. N. Shyamala, J. P. Naik, G. Sulochanamma and P. Srinivas, Chemical composition and antioxidant activity of the husk and endosperm of fenugreek seeds, LWT - Food Sci. Technol. 44 (2011) 451-456; https://doi.org/10.1016/j.lwt.2010.08.013 